\title{
An ethical journey for a life-long education for benefiting students, teachers, colleagues, and friends
}

\author{
Subhas K. Sikdar
}

Published online: 2 October 2014

(C) Springer-Verlag Berlin Heidelberg (Outside the USA) 2014

This journal's readers, reviewers, and contributing authors knew Prof. Ravi Jain as the Co-Editor-in Chief. I came to know Ravi for the first time when both had an urge to found a technical journal. It just turned out that Springer responded positively to both of us and shortly thereafter Ravi and I decided to merge our respective journals and Clean Technologies and Environmental Policy was born. Through the years we worked together on several projects and became trusted friends. It has been a long but very satisfying working relationship with Ravi.

Prof. Jain has spent more than a decade of successful tenure at the University of the Pacific at Stockton, California as the Dean of Engineering and Computer Science. He has been both effective and popular, a rare combination in academia. When he retired from the University, he thought it was time for him also to retire from his CoEditorship of the journal. More than the Dean and journal editing, Ravi has been a consummate educator since early 1990s when he started as Associate Dean of Engineering at the University of Cincinnati, about the time I arrived in the city.

Ravi, however, is an engineer as well. He started his career in environmental engineering at real world scales early in his career after completing his Ph.D. from Texas Tech. Although his managerial and administrative stint started at the Army Civil Engineering Research Laboratory (CERL) in Urbana-Champagne, Illinois, he kept his customary academic leaning by associating with the University of Illinois by teaching courses and joining research efforts. There he grew a particular interest in environmental policy. He knew that policy is an important element of the solution. Right policy makes better environmental outcomes; the wrong ones lead to dissensions and conflicts.

While at CERL, he had the enviable opportunity of studying at the Harvard University and Cambridge University (UK). These experiences expanded his knowledge horizon tremendously. He fondly talks about his associations with these universities and mentions his learning encounters with great minds there. His interest in policy culminated in several courses taught on this field and resulted in several books that have gone through multiple printing and updates and have even been translated in other languages. Ravi offers a policy thought piece in this issue on the very relevant issue of hydraulic fracturing or fracking. Here too, he truthfully presents the facts on both sides of this highly politicized issue and offers a template of solution based on partnerships of all involved parties. Usually one is either in favor of fracking or against it, depending on one's political leanings. Ravi, however, shows here that when all parties are looking at the data together there is less room for chicanery.

Ravi is still busy as ever, as a Professor and Dean Emeritus, in undertaking some research projects, working with universities internationally, where he has visiting distinguished professor appointments to teach both engineering and policy options to solve problems. I have been blessed with a colleague and friend like Ravi Jain, and it is an honor to dedicate this issue as Ravi Jain Special. 